\title{
Interpersonal Dynamics in a Simulated Prison
}

\author{
A Methodological Analysis
}

\author{
ALI BANUAZIZI Boston College \\ SIAMAK MOVAHEDI Department of Sociology, \\ University of Massachusetts-Boston ${ }^{1}$
}

Studies by psychologists in the field of 'corrections have generally focused on the psychological dispositions, personality traits, and attitudes of prisoners and guards, or on the relative efficacy of various treatment models and interventions on the inmates' behavior within the walls of the institutions and their social and psychological functioning following their release. These studies have been primarily person centered, both in their search for a constellation of psychological characteristics that distinguish the criminal offender from other members of society and in their proposed solutions for correctional reform. Hence, in defining the problems of prisons in primarily dispositional and interpersonal terms, psychologists have tended to view prison reform programs as limited to attempts to rehabilitate the inmates, sensitize the guards, or foster a more amicable relationship between the two groups.

Zimbardo and his associates (Haney, Banks, \& Zimbardo, 1973; Zimbardo, Haney, Banks, \& Jaffe, 1972, 1973a, 1973b) sought to challenge seriously this limited, if not distorted, approach to the study of imprisonment at a time when concern with the necessity of major institutional reforms in this field is at its highest among both the professionals and the concerned citizenry. The authors attempted to demonstrate that the social-structural, interpersonal, and psychological characteristics of prisons as such, rather than the individual dispositions of the guards or the inmates, are responsible for their failure as

\footnotetext{
${ }^{1}$ The authors are grateful to Norman H. Berkowitz, Ramsay Liem, and Don Mixon for their helpful comments on an earlier draft of this article.

Requests for reprints should be sent to Ali Banuazizi, Department of Psychology, Boston College, Chestnut Hill, Massachusetts 02167.
}

institutions and the grave human toll that they exact in the form of atrocities, suffering, degradation, and embitterment. Their study purportedly demonstrated that normal, healthy college students, when confined in a mock prison in which their keepers are their own normal, healthy peers, display in the course of a few short days an incredible array of intense and often pathological reactions, including loss of personal identity, passivity, depression, and helplessness. Meantime, their peers in the role of correctional officers tend to exhibit a remarkable capacity for tormenting, exploiting, and dehumanizing the inmates in discharging their duties.

Our purpose in this article is to analyze critically the main aspects of this significant and timely study. In spite of our full endorsement of the effort by Zimbardo and his coinvestigators to promote a structural analysis of the problems of imprisonment ${ }^{2}$, we wish to call into question, on primarily methodological grounds, some of the conclusions of their study. In addition to a critical examination of certain key assumptions of the authors in interpreting their data, which cast doubt on the plausibility of their final causal inferences, we shall offer some empirical

\footnotetext{
$<$ Haney, Banks, and Zimbardo (1973) stated that "the dispositional hypothesis has been embraced by the proponents of the prison status quo (blaming conditions on the evil in the prisoners), as well as by its critics (attributing the evil to guards and staff with their evil motives and deficient personality structures) [p. 711." This statement, although not quite unfounded, tends to overlook a considerable body of literature in the sociological tradition. To mention but a few outstanding examples, Clemmer (1958), Cressey (1959, 1965), Cloward (1960), Goffman (1961), Grusky (1959), McCorkle and Korn (1954), Polsky (1962), Schrag (1954), Sykes (1958), Weber (1957), and Wheeler (1961) have all focused their research on the study of prison as a social and bureaucratic structure.
} 
evidence of our own to elucidate and buttress some of our criticisms, and develop an alternative interpretation of their findings.

\section{An Overview of the Stanford Prison Experiment}

The study by Zimbardo and his associates (hereafter referred to as the Stanford Prison Experiment) was conducted in the summer of 1971 in a mock prison constructed in the basement of the psychology building at Stanford University. The subjects were selected from a pool of 75 respondents to a newspaper advertisement asking for paid volunteers to participate in a "psychological study of prison life." The 24 subjects who were chosen were male college students, largely from middleclass backgrounds, who were judged by the experimenters to be the "most stable (physically and mentally), most mature, and least involved in antisocial behaviors [Haney et al., 1973, p. 73]." On a random basis, half of the subjects were assigned to the role of guard and half were assigned to the role of prisoner.

Prior to the experiment, the subjects were asked to sign a form with the following stipulations: (a) All subjects would agree to play either the prisoner or the guard role for a maximum of two weeks; (b) those assigned to the prisoner role should expect to be under surveillance, to be harassed, and to have some of their basic rights curtailed during their imprisonment, but not to be physically abused; and (c) in return, the subjects would be guaranteed a minimally adequate diet, clothing, housing, medical care, and financial remuneration at the rate of $\$ 15$ per day for the duration of the experiment.

One day before the start of the experiment, the guards were invited to an orientation meeting. They were informed that the goal of the study was to "simulate a prison environment within the limits imposed by pragmatic and ethical considerations," and that their task was "to maintain the reasonable degree of order within the prison necessary for its effective functioning." The prisoner subjects were telephoned and asked to be available at their homes on a given Sunday at which time the study would begin. Subsequently, with the cooperation of the Palo Alto City Police Department, the subjects were apprehended in a "surprise [?] mass arrest." After going through an elaborate arrest and booking procedure, the subjects were blindfolded and driven to the mock prison.

Although the authors did not have any specific hypotheses to test, the general purpose of the study was to explore the interpersonal dynamics of a prison environment through a functional simulation of a prison in which no prior dispositional differences existed between prisoners and guards, and each group played its respective role for a maximum of two weeks.

The outcome of the study was quite dramatic and not entirely expected by the authors. In less than two days after the initiation of the experiment, violence and rebellion broke out. The prisoners ripped off their clothing and their identification numbers and barricaded themselves inside the cells while shouting and cursing at the guards. The guards, in turn, began to harass, humiliate, and intimidate the prisoners. They used sophisticated psychological techniques to break the solidarity among the inmates and to create a sense of distrust among them. In less than 36 hours, one of the prisoners showed severe symptoms of emotional disturbance, disorganized thinking, uncontrollable crying and screaming, and was released. (Later, there was a rumor that he had been faking and had won his release under false pretenses.) Soon the prisoners asked that a grievance committee be established and church services provided. On the third day, a rumor developed about a mass escape plot, which prompted the guards and the superintendent (Professor Zimbardo), who was operating in the background, to take various preventive measures. The guards, in the meantime, increased their harassment, intimidation, and brutality toward the prisoners. On the fourth day, two prisoners showed symptoms of severe emotional disturbance and were released, while a third prisoner developed a psychosomatic rash all over his body. He was also released. On the fifth day, the prisoners showed symptoms of individual and group disintegration. They had become mostly passive and docile, suffering from an acute loss of contact with reality. The guards, on the other hand, had kept up their harassment, some behaving sadistically and "delighting in what could be called the ultimate aphrodisiac of power [Zimbardo et al., 1972].”

The main findings of the study were summarized by the authors as follows:

All these data sources [i.e., observations of behavioral interactions, videotape recordings, questionnaires, self-report scales, and interviews] converge on the conclusion that this simulated prison developed into a psychologically compelling prison environment. 
As such, it elicited unexpectedly intense, realistic and often pathological reactions from many of the participants. The prisoners experienced a loss of personal identity and the arbitrary control of their behavior which resulted in a syndrome of passivity, dependency, depression and helplessness. In contrast, the guards (with rare exceptions) experienced a marked gain in social power, status and group identification which made role-playing rewarding [Haney et al., 1973, p. 691.

\section{Problems of Interpretation}

Many aspects of the Stanford Prison Experiment resemble, though in somewhat exaggerated form, what goes on in a real prison. The fact that such dramatic results were obtained in such a short time span, taken at its face value, would suggest that the experimenters were quite successful in functionally simulating a prison. On the other hand, it is possible that certain conditions and characteristics of the experiment itself, rather than the relevant experimental variables, produced the outcome, that is, the subjects' behavioral and emotional reactions. The latter possibility is what we shall argue for in the balance of this article.

Generally, in interpreting the behavioral outcomes of their study, Zimbardo and his associates seemed to rely upon two major assumptions: (a) They succeeded in functionally simulating a prison, that is, in creating a "psychologically compelling prison environment"; and (b) the "demand characteristics" (Orne, 1962, 1969) of the experiment and conscious role playing by the subjects were not of sufficient moment to determine the outcomes. Based on these assumptions, they inferred that the substantial and dramatic differences in the behavior and emotional reactions between the guards and the prisoners were due to their occupancy of different positions within the institutional structure and the situational and social-psychological contingencies prevailing in the prison, rather than to dispositional differences between the two groups of subjects or other confounding variables. We shall examine each of these assumptions.

SUCCESS OF THE SIMULATION

The prison created by Zimbardo and his associates certainly had most of the morphological features of a real prison: a cellblock, bars, guards, warden, superintendent, parole board, grievance committee, anonymity of a uniform, loss of name and personal property, harassment and intimidation by guards, etc. However, the theoretical inference that the same intervening processes are operative under a simulated set of conditions as in a natural setting requires that the two situations be demonstrated to be genotypically, rather than phenotypically, similar (Zelditch \& Evan, 1962). In social-psychological research this requirement is generally taken to mean that the experimental (simulated) conditions should have approximately the same symbolic and phenomenological significance to the subjects as their real-life analogues. In the case of a prison, since a myriad of situational characteristics and interpersonal processes might be potentially responsible for eliciting the behavioral, attitudinal, and emotional responses of guards and prisoners, a study of the social-psychological dynamics of prison life must specify the theoretically significant variables and processes that it attempts to simulate in the laboratory. In the absence of a systematic set of propositions about the social-psychological dynamics of prison life, it would be difficult to evaluate the functional correspondence between the mock prison and a real prison-and thus the success of the simulation.

Nevertheless, if some of the conditions and processes in a real prison lead to the mortification of the inmate's self, as the authors have suggested, then the subjective implications of the analogous conditions and processes in a simulated prison should be similarly interpreted by the mock prisoners. In the words of a leading student of "total institutions,"

the social arrangements must be "read" by the individual and others for the image of himself that they imply. [For instance,] according to the general expressive idiom of our society, having one's head shaved is easily perceived as a curtailment of the self, but while this mortification may enrage a mental patient, it may please a monk [Goffman, 1961, pp. 47-481.

In the Stanford Prison Experiment, the prisoners had to wear caps made of women's nylon stockings as a functional simulate of shaving their heads. The symbolic significance of the two procedures is likely to be perceived very differently: While a shaved head for a prisoner is a constant reminder of his being rejected, cast out, and found indecent, a nylon cap for a prisoner in the Stanford prison was a constant reminder of his participation in a scientific experiment, a rather honorable and courageous act. Similarly, the phenomenological significance of the loss of freedom in the mock prison and the real prison is vastly different.

[Tlhe wall that seals off the criminal, the contaminated man, is a constant threat to the prisoner's self conception and the threat is constantly repeated in the many daily reminders that he must be kept apart from "decent" men [Sykes, 1958, p. 67]. 
However, the walls that sealed off the subjects in the Stanford prison were reminders, again, of their voluntary involvement in an adventurous scientific research, a source of possible ego-satisfaction. To cite yet another example, the arrest and initial incarceration procedures in the study could hardly be considered a functional simulation of what Garfinkel (1958) has called "degradation ceremonies." Considering that the prisoner subjects had been informed by telephone to be present at their homes on a given Sunday, at which time the experiment would begin, the authors would have to impute an exceptional degree of naiveté to their college student subjects to believe that they were not conscious of their status in a scientific game, which would not be seen as self-degrading.

\section{DEMAND CHARACTERISTICS AND ROLE PLAYING}

Zimbardo and his associates acknowledged, but argued against, the possibility that the dramatic outcomes of their experiment could be explained on the basis of its inherent demand characteristics and conscious role playing by the subjects. They have maintained that the subjects were soon (i.e., almost from the very first day) engrossed in their roles, had their sense of reality transformed, and were thus acting realistically in response to the structural characteristics and the interpersonal dynamics of the prison. ${ }^{3}$ They offer the following as possibly the strongest evidence to substantiate this ad hoc hypothesis of reality transformation:

\footnotetext{
3 This is a curious conception of "reality" and its loss and transformation. Yet, it appears to be an important part of the ideological rhetoric of many psychiatrists and clinical psychologists. As such, it is largely responsible for the involuntary commitment of thousands of people to mental institutions.

Ironically, almost everyone who had some direct or indirect involvement in the Stanford Prison Experiment had his or her sense of reality transformed at one time or another during the course of the experiment. As early as the second day of the experiment, the loss of sense of reality among the subjects assumed "pathological" proportions. The prisoners came to believe that they were confined in a real prison on some real criminal charges; having lost all hope of escape, they asked for church services to pray to the Lord for their release on parole. On the third day, Professor Zimbardo himself admittedly showed some symptoms of reality transformation. On the fourth day, a former prison chaplain visited the prison and, promptly losing his sense of reality, responded to the subjects as though they were real prisoners and disparaged them for not taking any legal action to be released. On the fifth day, some of the parents apparently lost their sense of reality. One parent, for instance, gave the superintendent
}

During a parole board hearing ... . each of five prisoners eligible for parole was asked by the senior author whether he would be willing to forfeit all the money earned as a prisoner if he were to be paroled (released from the study). Three of the five prisoners said, "yes," they would be willing to do this. Notice that the original incentive for participating in the study had been the promise of money [Haney et al., 1973, p. 93; italics added].

To Zimbardo and his associates, the fact that three of the five prisoners were willing to forfeit all the money that they had earned in return for parole was an indication of the transformation of the subjects' sense of reality and their loss of identity, that is, that they no longer perceived themselves as subjects participating in an experiment for money. On the other hand, if the willingness of three prisoners to forfeit their earnings is regarded as confirming evidence for the reality transformation hypothesis, should not the refusal of two other subjects in the same study to forfeit all of the money that they had earned be regarded as disconfirming evidence for this hypothesis?

Furthermore, although three of the prisoners were willing to forfeit the money that they had earned to be granted parole, it is not clear whether they would have done the same in order to quit the experiment. Zimbardo and his coinvestigators make no distinction between leaving the experiment and leaving the prison. But, one who is paroled, bailed out, or even escapes from a prison is still a subject in the experiment. These are all important aspects of being a prisoner. Thus, to be paroled would not be in violation of what Orne (1962) called a contextually binding agreement of the subject "to participate in a special form of social interaction known as taking part in an experiment' [p. 777]." However, to quit the experiment (i.e., to go to the experimenter and request that one be relieved of one's role as a subject) is indeed a violation of that agreement. Hence, it is not particularly surprising that the prisoners in the experiment were contemplating escape on the second day and were willing to forfeit their money to be

(Professor Zimbardo) the telephone number of her cousin, a public defender, who would legally represent her son. It appears that the last person who was just about to lose his sense of reality was this public defender who came to prison to discuss seriously sources of bail money with the prisoners (Zimbardo et al., 1972, 1973b). We can only be grateful for the fact that the experiment was terminated after six days. We wonder how many other people and responsible officials might have had their sense of reality transformed had the experiment run its full course! 
paroled on the fourth day, but apparently they did not express an intention to quit the experiment as subjects. ${ }^{4}$

As a number of relatively recent social-psychological experiments have demonstrated, frustrating and painful experiences do not always cause the experimental subjects to quit the experiment. In this connection, Orne (1962) pointed out that subjects agree

to tolerate a considerable degree of discomfort, boredom, or actual pain, if required to do so by the experimenter.... Just about any request which could conceivably be asked of the subject by a reputable investigator is legitimized by the quasi-magical phrase (or cognition) "This is an experiment" [p. 777].

Orne claimed that he has been personally unsuccessful in finding an experimental task, no matter how meaningless or frustrating, that would make the subjects leave the experiment.

The experimenter's expectation to find support for his hypothesis is a source of systematic bias (Rosenthal, 1969). We do not intend to address this problem in the Stanford Prison Experiment even though it does merit consideration, particularly in view of the principal investigator's active involvement in his experiment to the extent of having his sense of reality transformed, according to his own report (Zimbardo et al., 1972). Nevertheless, we consider his active role as superintendent to have provided strong cues regarding expected, or at least legitimate, patterns of behavior by all subjects. This is an especially cogent consideration in relation to the guards, who were, of course, functioning under his direct authority. Thus his position and his unusually active role in the experiment could have added to the various other demand characteristics in the situation.

In brief, then, we believe that Zimbardo and his coauthors failed to make a compelling case against

\footnotetext{
${ }^{4}$ The fact that on the occasion of a visit by a Catholic priest some of the prisoners referred to themselves by their prison identification numbers, rather than their Christian names, has been offered by the authors as further evidence for their reality transformation hypothesis. Since to our knowledge real prisoners rarely, if ever, introduce themselves to outsiders, particularly a sympathetic visitor, by their official prison numbers, we can only interpret the behavior of their subjects as a case of overzealous role players attempting to be more Catholic than the Pope. Furthermore, the authors report that some of the guards were willing to work overtime with no additional pay, taking this fact, also, as further support for the reality transformation argument. Again, it appears that the subjects in the experiment had a somewhat unrealistic conception of real guards and the latter's sense of dedication to duty.
}

the determining effects of the demand characteristics of their experimental situation on their subjects. To put it more precisely, they hardly addressed these crucial questions. The notion of reality transformation that they put forth is at best an unsubstantiated ad hoc hypothesis to support a particular interpretation of the findings.

\section{An Alternative Explanation of the Experiment's Outcome}

In the light of the preceding analysis, we maintain that the subjects in the Stanford Prison Experiment were not placed in a social situation functionally equivalent to a real prison. They were asked to play the roles of prisoner and guard on a phenol-typically similar stage. ${ }^{5}$ To account for the behavioral outcomes of the experiment, we offer the following alternative explanation: (a) The subjects entered the experiment carrying strong social stereotypes of how guards and prisoners act and relate to one another in a real prison; (b) in the experimental context itself, there were numerous cues pointing to the experimental hypothesis, the experimenters' expectations, and possibly, the experimenters' ideological commitment; and thus (c) complying with the actual or perceived demands in the experimental situation, and acting on the basis of their own role-related expectancies, the subjects produced data highly in accord with the experimental hypothesis.

We have already discussed some of the demand characteristics of the experimental situation. To evaluate the extent to which the two other tenets of our interpretation, that is, the subjects' stereotypic expectations of prisoner and guard roles prior to the experiment and their cognizance of the experimental hypothesis, could have potentially influenced the outcome of the experiment by Zimbardo and his associates, we prepared a questionnaire and administered it to a group of 185 college students in the greater Boston area. ${ }^{6}$

The questionnaire contained a brief description of the procedures followed in the Stanford Prison

\footnotetext{
${ }^{\mathrm{b}}$ In fact, even Zimbardo and his associates admit that when the guards were questioned after the study "about their persistent affrontive and harassing behavior in the face of prisoner emotional trauma, most guards replied that they were just playing the role' of a tough guard [Haney, et al., 1973, pp. 92-93; emphasis added]."

${ }^{6}$ The general idea of this study was suggested by Orne (1962).
} 
Experiment, including:

1. A note similar to the advertisement used in the original study to recruit subjects: "College students needed for psychological study of prison life. \$15 per day for one to two weeks ...."

2. A description of some of the rights and privileges that they had to give up temporarily in order to participate in the experiment (similar to the contract that was signed by the subjects in the study itself): "To participate, you will have to stay in a prison for one to two weeks. You will have to give your consent to be under surveillance, to be harassed, and have your civil rights curtailed for the entire period of the experiment ...."

3. An account of the actual arrest and booking procedures and the type of treatment that they would receive in the initial phase of their incarceration:

Suppose you decide to participate, and you sign the proper release forms. On a subsequent Sunday morning, a police officer knocks on your apartment door and arrests you. He charges you with a felony, warns you of your constitutional rights, searches you, handcuffs you, and in the back of his car, takes you to the police station for booking. You are then fingerprinted, and left in an isolated detention cell. After a while, you are blindfolded and sen to a prison. There, you are stripped naked, skin searched, deloused, and issued a uniform, bedding, soap, towel, toothpaste, and toothbrush. And all this time you have been pushed around, put down, and humiliated.

The above description of the experiment was followed by a number of open-ended questions to determine the respondents' awareness of the experimental hypothesis and their expectancies regarding the outcomes of the experiment.

The number of returned questionnaires used in the following analyses was 150 because 35 of the students indicated having some prior knowledge of the Stanford experiment. In spite of the fact that the amount of information about the experiment provided on the questionnaire, compared to the full range of situational and interpersonal cues to which the subjects in the Stanford Prison Experiment were exposed, was relatively meager, the overwhelming majority of the respondents (81\%) were able to articulate quite accurately the intent of the experiment, that is, its general hypothesis. The following responses to the question "What would you say the experimenter is trying to prove?" are representative:

S1014: Experimenter is trying to prove the contention that he has about jails. He believes that people are pushed about, put down, and humiliated in jails and other correctional institutions.
S1029: Testing endurance-to see how far you go before fighting back, I think they are trying to find out what causes prison riots. S1053: He is trying to find out if anybody would fit into either of the two roles. That is, figuring that everyone is equal, a person selected as a guard will behave, act, and become like a guard; if a person is selected to be a prisoner, he will act, behave, and become like a prisoner.

Four questions on the form inquired into the respondents' expectations regarding the outcome of the experiment. Specifically, they were asked: (a) to describe the behavior and attitudes of the guards in such a prison; (b) to predict what the prisoners would do in this situation; (c) to describe how they would have behaved if they were to play the role of a guard in this prison; and (d) to describe how they would have behaved if they were picked as a prisoner.

The respondents' predictions regarding the behavior and attitudes of the guards (Questions a and c above) were analyzed separately from their predictions concerning prisoners' behavior (Questions $b$ and $\mathrm{d}$ above). In each case the same categories were used for coding predictions about guards or prisoners in general, or about the respondents' own behavior in the roles of guard or prisoner. The categories for coding the behavior of guards were: (a) oppressive, hostile, aggressive, humiliating, etc.; (b) fair, concerned, neutral, lenient, etc.; and (c) other, including "don't knows," vague answers, etc. Predictions about prisoners' behavior were coded according to the following categories: (a) rebellious, defiant, aggressive, etc.; (b) passive, docile, compliant, model prisoner, etc. ; (c) fluctuating, depending upon the behavior of the guards; and (d) other, including "don't knows," vague answers, etc. The above coding categories were devised and applied by two research assistants who were unfamiliar with the purposes for which our questionnaire had been designed and administered. They had been asked to read all the responses to the questionnaire items and devise a coding scheme, with a small number of alternatives for each question, under which the respondents' predictions could be logically subsumed.

Table 1 shows the distribution of the respondents' predictions in terms of the alternative categories in our coding system. The top half of the table contains their predictions of how college students, in general, would behave if assigned to the roles of guard or prisoner in a prison experiment; the bottom half of the table presents the respondents' predictions regarding their own behavior in these roles and in such a situation. The data are presented separately by sex 
TABLE 1

Percentage of Different Predictions by Respondents Regarding Self- and Others' Behavior in the Roles of Guard or Prisoner

\begin{tabular}{|c|c|c|c|c|c|c|c|c|c|c|}
\hline \multirow{3}{*}{$\begin{array}{l}\text { Referent of } \\
\text { prediction }\end{array}$} & \multirow{3}{*}{$\begin{array}{l}\text { Respondent's } \\
\text { sex }\end{array}$} & \multicolumn{9}{|c|}{ Predicted behaviors } \\
\hline & & \multicolumn{4}{|c|}{ When assigned to guard role } & \multicolumn{5}{|c|}{ When assigned to prisoner role } \\
\hline & & $\begin{array}{c}\text { Oppressive } \\
\text { hostile } \\
\text { etc. }\end{array}$ & $\begin{array}{c}\text { Lenient, } \\
\text { fair, } \\
\text { etc. }\end{array}$ & Other & Total & $\begin{array}{c}\text { Rebellious, } \\
\text { defiant, } \\
\text { etc. }\end{array}$ & $\begin{array}{c}\text { Passive, } \\
\text { docile. } \\
\text { etc. }\end{array}$ & Fluctuating & Other & Total \\
\hline \multirow[t]{6}{*}{ Others } & \multirow[t]{2}{*}{ Male } & 85.1 & 10.4 & 4.5 & 100.0 & 23.5 & 38.2 & 32.4 & 5.9 & 100.0 \\
\hline & & (57) & (7) & (3) & (67) & (16) & (26) & (22) & (4) & (68) \\
\hline & \multirow{2}{*}{ Female } & 93.8 & 1.2 & 4.9 & 100.0 & 39.0 & 25.6 & 29.3 & 6.1 & 100.0 \\
\hline & & (76) & (1) & (4) & (81) & (32) & (21) & (24) & (5) & (82) \\
\hline & \multirow[t]{2}{*}{ Both sexes } & 89.9 & 5.4 & 4.7 & 100.0 & 32.0 & 31.3 & 30.7 & 6.0 & 100.0 \\
\hline & & (133) & (8) & (7) & (148) & (48) & (47) & (46) & (9) & $(150)$ \\
\hline \multirow{6}{*}{ Self } & \multirow[t]{2}{*}{ Male } & 48.4 & 33.9 & 17.7 & 100.0 & 15.6 & 18.8 & 32.8 & 32.8 & 100.0 \\
\hline & & (30) & (21) & (11) & (62) & (10) & (12) & (21) & (21) & (64) \\
\hline & \multirow{2}{*}{ Female } & 46.3 & 38.8 & 15.0 & 100.0 & 12.7 & 40.5 & 17.7 & 29.1 & 100.0 \\
\hline & & (37) & (31) & (12) & (80) & (10) & (32) & (14) & (23) & (79) \\
\hline & \multirow[t]{2}{*}{ Both sexes } & 47.1 & 36.6 & 16.2 & 100.0 & 14.0 & 30.8 & 24.5 & 30.8 & 100.0 \\
\hline & & (67) & (52) & (23) & (142) & (20) & (44) & (35) & (44) & (143) \\
\hline
\end{tabular}

Note. Numbers in parentheses indicate frequencies of the different predictions by the respondents; frequency totals that are less than 150 , the total number of respondents, resulted from unscorable responses to items in a particular category.

in order to allow a comparison of the findings with those of Zimbardo and his associates, who used only male subjects in their experiment, and to reveal any possible differences between males and females in responses to the various questionnaire items.

As the summary of the data in Table 1 indicates, the vast majority of the respondents (89.9\%) predicted that the behavior of guards toward prisoners would be oppressive, hostile, aggressive, etc. Such phrases as "animal-like," "extremely authoritarian," and "overpowering and vicious" were used frequently to characterize the behavior of the guards. There was no such consensus, on the other hand, in the respondents' predictions concerning how inmates would be likely to behave in such an experiment. The greater variability in these predictions, compared to the rather uniform predictions about the guards, seems to reflect the more diffuse nature of the popular conceptions of the role of prisoner.

The respondents' answers to the items asking about how they themselves would behave in such a prison as guards or prisoners were also distributed more evenly among the several categories used in our coding system (see Table 1). Thus, for example, only about half (47.1\%) of the respondents predicted that as guards they would act aggressively or viciously toward the prisoners; only $14 \%$ predicted that as prisoners they would be rebellious or defiantly aggressive. Given the socially undesirable nature of admitting that one's behavior toward one's own peers would be aggressive or abusive, discrepancies between the two sets of predictions (about others and about oneself) could be expected. A closer inspection of the individual responses to the pertinent items on the questionnaire revealed that when the referent group was changed from others to the self, predictions tended to become considerably more guarded and less confident. Thus, the number of "I don't know," vague, or blank responses in predictions concerning both the guards' and the prisoners' behaviors showed at least a fourfold increase when the respondents were predicting their own behavior in these roles in comparison to when they were predicting the behavior of others in the same situation.

Finally, while an adequate comparison between sexes in their responses to the items on the questionnaire cannot be made on the basis of the present data (and such a comparison is not germane to our critique), it is interesting to point briefly to some trends. It appears that the female respondents had an even more "tough guy" image of guards in making their predictions-only 1 of 81 female respondents predicted that the guards would be fair or lenient in their behavior toward the prisoners. In predicting the behavior of prisoners in general, females saw them as being more rebellious or defiant 
(39\%) than did males (23.570). However, in predicting how they themselves would perform in the role of prisoner, twice as many females (40.5 7c) than males $(18.87 c)$ responded by characterizing their projected behavior as passive or compliant.

\section{Conclusion}

We have offered an alternative interpretation of the dramatic outcome of the Stanford Prison Experiment. In our view, the subjects responded to a number of demand characteristics in the experimental situation, acting out their stereotypic images of a prison guard and, to a lesser extent, of a prisoner. To the extent that such confounding variables were operative, the subjects' behavior cannot be explained as strategic, coping responses to an asymmetrical power situation analogous to that of a real prison. The data obtained from our respondents to a questionnaire that had been designed especially to evaluate the validity of certain tenets of our analysis tend to support such an interpr6tation.

It may be argued, of course, that our questionnaire tapped only the respondents' attitudes vis-à-vis the prisoner and guard roles, and that as such their attitudes and predictions should not be taken as valid indicators of how they or others would behave in a simulated or real prison. The relationship between attitudes and overt behavior is a highly problematic one and has been the subject of a number of recent reviews (Calder \& Ross, 1973; Ehrlich, 1969; Wicker, 1969). Thus, the possibility of inconsistencies between the reported respondents' predictions and their overt behavior in the context of a prison or a prison experiment cannot be ruled out. On the other hand, the relationship between role playing and behavior in a natural setting presents a problem which is no less vexatious.' As Miller (1972) pointed out in his analysis of the current controversy over role playing versus deception, "Even if role playing produces data comparable in its topography to actual behavior, it is not precisely the

Both Milgram (1963) and Freedman (1969) were able to obtain few, if any, "obedience responses" from students who had been asked to predict the outcome of Milgram's original obedience study. However, as Mixon (1973) has shown, this may have been due to their incomplete description of the experimental conditions. Predictions of obedience ranging from 0 to $90 \%$ have been obtained by Mixon through slight variations in his descriptions of Milgram's study. same thing as the actual behavior in its antecedent and theoretical properties [p. 634]."

In our view, role playing may best be regarded as a good strategy for assessing an individual's attitude toward a specific psychological object, rather than a technique for (re-)discovering what goes on in a real-world situation with the hope of being able to disentangle, a posteriori, the critical processes therein. The currently fashionable viewpoint that through role playing one can evaluate the impact of certain structural variables on social behavior represents little more than a reification of concepts like role, status, and power, and a literal apprehension of the dramaturgical interpretation of social behavior. Such a view would suggest, for example, that the social psychological impact of institutionalized racism and social inequality on blacks in the United States could be studied through the simulation of the relevant structural variables in a laboratory situation with white subjects playing the role of blacks.

Finally, a major implication of our analysis is that when experimental subjects are asked to play highly stereotyped and emotion-laden roles, they bring to the experimental situation "mental sets," or dispositions, which could decisively influence their behavior. While these mental sets are not the same as the more idiosyncratic personality traits, they do constitute strong propensities to act out culturally conditioned images. This is particularly the case when a concordance exists between these images of the subjects and the demand characteristics of the experiment. If valid, this proposition would seriously challenge the use of role playing as a strategy for testing dispositional versus situational hypotheses-the primary goal of the study by Zimbardo and his associates.

\section{REFERENCES}

Calder, B. J., \& Ross, M. Attitudes and behavior. Morristown, N.J.: General Learning Corporation, 1973.

Clemmer, D. The prison community. New York: Rinehart, 1958.

Cloward, R. A. Social control in the prison. In R. Cloward et al. (Eds.), Theoretical studies in social organization of the prison. New York: Social Science Research Council, 1960.

Cressey, D. R. Contradictory directives in complex organizations: The case of the prison. Administrative Science Quarterly, 1959, 4, 1-19.

Cressey, D. R. Prison organizations. In J. G. March (Ed.), Handbook of organizations. Chicago: Rand McNally, 1965. 
Ehrlich, J. Attitudes, behavior, and the intervening variables. American Sociologist, 1969, 4, 29-34.

Freedman, J. L. Role playing: Psychology by consensus. Journal of Personality and Social Psychology, 1969, 13, 107-114.

Garfinkel, H. Conditions of successful degradation ceremonies. American Journal of Sociology, 1958, 61, 420424.

Goffman, E. Asylums. New York: Doubleday, 1961.

Grusky, O. Role conflict in organization: A study of prison camp officials. Administrative Science Quarterly, 1959, 3,452-472.

Haney, C., Banks, W. C., \& Zimbardo, P. G. Interpersonal dynamics in a simulated prison. International Journal of Criminology and Penology, 1973,1,69-97.

McCorkle, L. W., \& Korn, R. Resocialization within walls. Annals of the American Academy of Political and Social Science, 1954, 293, 80-98.

Milgram, S. Behavioral study of obedience. Journal of Abnormal and Social Psychology, 1963, 67, 371-378.

Miller, A. G. Role playing: An alternative to deception? A review of the evidence. American Psychologist, 1972, 27, 623-636.

Mixon, D. Instead of deception. Journal of the Theory of Social Behaviour, 1973, 2, 145-177.

Polsky, H. W. Cottage six. New York: Russell Sage Foundation, 1962.

Orne, M. T. On the social psychology of the psychological experiment: With particular reference to demand characteristics and their implications. American Psychologist, 1962,17,776-783.

Orne, M. T. Demand characteristics and the concept of quasi-controls. In R. Rosenthal \& R. L. Rosnow (Eds.),
Artifact in behavioral research. New York: Academic Press, 1969

Rosenthal, R. Interpersonal expectations: Effects of the experimenter's hypothesis. In R. Rosenthal \& R. L. Rosnow (Eds.), Artifact in behavioral research. New York: Academic Press, 1969.

Schrag, C. Leadership among inmates. American Sociological Review, 1954, 19, 37-42.

Sykes, G. M. The society of captives. Princeton, N.J.: Princeton University Press, 1958.

Weber, G. H. Conflict between professional and nonprofessional personnel in institutional delinquency treatment. Journal of Criminal Law, Criminology and Police Science, 1957, 48, 26-43.

Wheeler, S. Socialization in correctional communities. American Sociological Review, 1961, 26, 697-712.

Wicker, A. W. Attitudes versus action: The relationship of verbal and overt behavioral responses to attitude objects. Journal of Social Issues, 1969, 25, 41-78.

Zelditch, M., Jr., \& Evan, W. M. Simulated bureaucracies: A methodological analysis. In H. Guetzkow (Ed.), Simulation in social science. Englewood Cliffs, N.J.: Prentice-Hall, 1962.

Zimbardo, P. G., Haney, C., Banks, W. C., \& Jaffe, D. Stanford prison experiment. Stanford, Calif.: Philip G. Zimbardo, Inc., 1972. (Tape recording)

Zimbardo, P. G., Haney, C., Banks, W. C., \& Jaffe, D. A Pirandellian prison: The mind is a formidable jailer. New York Times Magazine, April 8, 1973, pp. 38-60. (a)

Zimbardo, P. G., Haney, C., Banks, W. C., \& Jaffe, D. The psychology of imprisonment: Privation, power and pathology. Unpublished manuscript, Stanford University, 1973. (b) 